\title{
Obesity as a Conditioning Factor for High-Altitude Diseases
}

\author{
Rocío San Martin $^{a} \quad$ Julio Brito ${ }^{a}$ Patricia Siques ${ }^{a}$ Fabiola León-Velarde ${ }^{b}$ \\ ${ }^{a}$ Institute of Health Studies, Universidad Arturo Prat, Iquique, Chile; ${ }^{b}$ Department of \\ Biological and Physiological Sciences. Facultad de Ciencias y Filosofía/ IIA, Universidad \\ Peruana Cayetano Heredia, Lima, Perú
}

\section{Keywords}

Hypoxia $\cdot$ High-altitude diseases $\cdot$ Obesity $\cdot$ Overweight $\cdot$ Conditioning factors

\begin{abstract}
Obesity, a worldwide epidemic, has become a major health burden because it is usually accompanied by an increased risk for insulin resistance, diabetes, hypertension, cardiovascular diseases, and even some kinds of cancer. It also results in associated increases in healthcare expenditures and labor and economic consequences. There are also other fields of medicine and biology where obesity or being overweight play a major role, such as high-altitude illnesses (acute mountain sickness, hypoxic pulmonary hypertension, and chronic mountain sickness), where an increasing relationship among these two morbid statuses has been demonstrated. This association could be rooted in the interactions between obesity-related metabolic alterations and critical ventilation impairments due to obesity, which would aggravate hypobaric hypoxia at high altitudes, leading to hypoxemia, which is a trigger for developing high-altitude diseases. This review examines the current literature to support the idea that obesity or overweight could be major conditioning factors at high altitude.
\end{abstract}

(C) 2017 The Author(s)

Published by S. Karger GmbH, Freiburg

\section{Introduction}

Obesity, as a consequence of nutritional transitions and particularly the 'westernization' of lifestyles, is a growing epidemic and a public health concern since obesity is usually associated with other serious comorbidities, such as type 2 diabetes mellitus, insulin resistance and ischemic cardiovascular disease [1,2]. Moreover, obesity is not only a public health problem but also has a serious impact on many human activities. Obese subjects are likely to 
be hypoxemic, and hypoxemia triggers the development of the main high-altitude diseases. The prevalence of high-altitude diseases varies according to exposure type, altitude and ethnicity, and can reach up to $60 \%$ for acute mountain sickness (AMS) and 10-15\% for highaltitude pulmonary hypertension (HAPH) [3]. The size of the population currently living above 2,500 $\mathrm{m}$ is estimated to be over 100 million [4]. Therefore, it is important to assess the mechanisms and relationships connecting high-altitude hypoxemia and obesity, which play a role in determining health statuses at high altitude.

Consequently, this review is focused on the current literature and the facts that associate obesity, as a relevant conditioning factor for high-altitude diseases, with its metabolic and physiological consequences. Additionally, it provides information that might be useful for tourists, travelers, workers, and mountaineers as well as for local physicians in mountain regions.

\section{High-Altitude Diseases}

The partial pressure of oxygen in inspired air falls with increasing elevation above sea level. As a consequence of hypobaric and hypoxic environments, humans at high altitudes develop numerous physiologic responses [5]. When these responses are not sufficient, highaltitude diseases are developed, such as AMS and its serious complications, high-altitude pulmonary edema (HAPE), and high-altitude cerebral edema (HACE), during acute exposure. Chronic mountain sickness (CMS) and HAPH can develop during chronic exposure [3]. Types of exposure to high altitude include acute (days), long-term chronic intermittent (in shifts), and chronic (permanent) exposure.

\section{Acute Exposure to High-Altitude Hypoxia and Acute Mountain Sickness}

AMS is a syndrome characterized by headache and is accompanied by nonspecific symptoms, including gastrointestinal complaints (lack of appetite; nausea and vomiting), fatigue, dizziness, and insomnia. It develops more frequently in non-altitude-acclimatized individuals who rapidly ascend to altitudes $>2,500 \mathrm{~m}[6,7]$. The estimated incidence rate ranges from $9 \%$ to $75 \%$, depending on the exposure to altitude, and shows a logarithmic trend [8-10]. AMS is not usually life-threatening, but it can seriously affect quality of health and decrease productivity [11]. In severe cases, AMS can lead to HACE and/or HAPE, both of which are potentially lethal $[6,12]$.

As soon as a hypoxic environment is reached by going to a higher altitude, the partial pressure of oxygen $\left(\mathrm{PO}_{2}\right)$ falls and hypoxemia develops within minutes of arrival. To limit the drop in the arterial oxygen content, cardiac output is increased through sympathetic activation, and alveolar ventilation is increased through the stimulation of peripheral chemoreceptors. The latter determines the success of acclimatization and, subsequently, the presence of any high-altitude diseases. Thus, the ventilatory response to hypoxia is a physiological cornerstone concept, and it depicts a characteristic ventilation pattern at high altitudes [13].

Recognized risk factors for AMS are the rate of ascent, altitude reached, duration of exposure, and individual susceptibility factors such as exercise habits, being under 50 years of age, ethnicity. and the presence of obesity $[6,14,15]$. 


\section{Chronic Intermittent Exposure to High-Altitude Hypoxia}

The impact of AMS has been a matter of special concern because it is not only an issue for climbers and tourists but also for an emerging type of altitude exposure that occurs as a consequence of mining and frontier labor, among other activities. This new model has been called long-term chronic intermittent exposure to high-altitude hypoxia (CIH) and has been coined as the 'Chilean miners' model of CIH exposure', which is clearly different from acute (alpinism), altitude training-related, obstructive sleep apnea-related, or chronic (permanent residence) exposure [16]. These activities involve populations commuting in shifts (usually ranging from 7 to 15 days) from low altitude or sea level to high altitude $(4,000 \mathrm{~m}$ to 4,500 $\mathrm{m}$ ) during working periods, followed by resting periods at their place of origin over the course of many years. The population experiencing this new kind of exposure, in Chile alone, includes over 250,000 people and is increasing [11].

The prevalence of benign AMS in the first 2 days of exposure to $\mathrm{CIH}$ has been estimated at approximately $20 \%[16,17]$. However, it has been demonstrated that the prevalence of AMS is even greater and scarcely changes over the time, remaining at up to $50 \%$ in a mild form, after 12 years or more spent working in these shifts [11,15].

\section{Chronic Hypoxia}

At high altitude, native populations and long-term residents develop numerous physiological responses. The most characteristic are an increase in hemoglobin (Hb) concentration and pulmonary arterial pressure (PAP). In severely hypoxic residents, large increases in their $\mathrm{Hb}$ concentration and/or PAP may be associated with potentially fatal illnesses, such as CMS and HAPH $[18,19]$. Patients with CMS usually have intermittent or permanent cyanosis, venous dilatation in their hands and feet, and a clubbing of the fingers and toes. In the advanced stages of the disease, right-side heart failure secondary to excessive pulmonary hypertension usually appears. In addition to the role played by hypoxia in the etiology of CMS, additional factors may be involved in its development: age, pulmonary dysfunction, and obesity may aggravate the hypoxemia. Blood oxygen desaturation that occurs while sleeping at high altitude is also considered a conditioning factor for the disease [3].

HAPH occurs in children and adults residing above 2,500 m. It is characterized by a mean PAP of $>30 \mathrm{~mm} \mathrm{Hg}$ or a systolic PAP of $>50 \mathrm{~mm} \mathrm{Hg}$ measured at the altitude of residence, right ventricular hypertrophy, heart failure, and moderate hypoxemia. CMS and HAPH are frequent and potentially fatal chronic hypoxia-related illnesses in high-altitude populations [3].

To emphasize the size of the population involved, it is worth noting that in South America, three of the four main Andean countries (Bolivia, Colombia, Ecuador, Perú) have their capitals (La Paz, Bogotá, Quito) at high altitude. In the Asian countries of Afghanistan, Bhutan, China, India, Kyrgyzstan and Nepal, up to $45 \%$ of their populations live above 2,500 m. In China alone, there are four high plateaus (Qinghai-Tibet, Inner Mongolia, Yun-Gui, and the Yellow Land Plateau) that have a total population of nearly 90 million people. In North America, Mexico and the western US have relatively smaller, but increasing high-altitude populations [4]. It is estimated that up to $5-10 \%$ of high-altitude inhabitants may develop CMS or HAPH [3]. 
San Martin et al.: Obesity as a Conditioning Factor for High-Altitude Diseases

\section{Obesity}

Obesity is a serious worldwide problem that involves hundreds of millions of people, according to the World Health Organization (WHO). There will be approximately 2.3 billion overweight people aged 15 years and above and over 700 million obese people worldwide in 2015 [20]. The BMI is used to define obesity. Being overweight is classified as a BMI of 25-29.9 $\mathrm{kg} / \mathrm{m}^{2}$, and obesity as a BMI over $30 \mathrm{~kg} / \mathrm{m}^{2}$ [21]. BMI appears to be strongly correlated with various metabolic and disease outcomes, although direct measures of body fat and its distribution, such as waist circumference, are better predictors [22,23]. Several factors contribute to obesity, e.g., genetics, an unhealthy lifestyle (physical inactivity, unhealthy diet), metabolic and environmental factors, socioeconomic status, and psychological issues [24]. Nevertheless, Western dietary patterns and unhealthy lifestyles have been suggested to be the most important factors leading to the widespread increase in obesity throughout all age groups $[25,26]$ and in people with all kinds of jobs. Ultimately, obesity results from a positive energy balance: when energy intake is greater than energy expenditure. Obesity has become a major health burden because it is usually accompanied by an increased risk for insulin resistance, diabetes, hypertension, cardiovascular diseases, and possibly some kinds of cancer as well as other diseases [27].

Finally, obesity has a very strong and direct impact on individuals' health, and its associated comorbidities lead to increasing healthcare expenditures and labor absenteeism [28, 29].

\section{Obesity and Acute Exposure to High Altitude}

Obesity and a history of migraines have been shown to be important risk factors for AMS [30], but the current knowledge about the prevalence of obesity and the associated factors in those working in high-altitude industries is very limited [31,32]. However, there is growing evidence that obese individuals are more susceptible to developing AMS than non-obese individuals during exposure to high-altitude-induced hypobaric hypoxia [33]. Moreover, despite the methodological limitations of most of these studies (altitude, BMI stratification, type of exposure, and age), which reduce the ability to draw a general conclusion, many relevant studies support the idea that obesity, or being overweight, is an important risk factor for AMS $[34,35]$. Honigman et al. [36] also suggested that obese individuals are more susceptible to acute high-altitude hypoxia than subjects with normal body weight.

In fact, subjects who are both lean and have low normal weight (BMI $<22 \mathrm{~kg} / \mathrm{m}^{2}$ ) have been shown to be less susceptible to AMS at 5,150 $\mathrm{m}$ than those who are of normal weight or are obese, with AMS incidence rates of $22 \%, 54 \%$, or $70 \%$ [34]. Male trekkers who have suffered from AMS around the Thorong Pass $(5,400 \mathrm{~m})$ had significantly higher BMIs than those who did not [37]. Under conditions of simulated hypoxia $(3,654 \mathrm{~m})$ in a hypobaric chamber, it has also been demonstrated that obesity predisposes people to AMS [33]. Conversely, there is research suggesting that there is no relationship between AMS and BMI at $5,671 \mathrm{~m}$, probably because the subjects in that study were very fit and trained trekkers [38].

In general, in studies of AMS development, risk profiling has been mostly focused on the physiological characteristics of an AMS-prone state, such as excessive desaturation under hypobaric conditions, a low ventilatory response to exercise, or variability in nitric oxide metabolism $[39,40]$. Therefore, any condition that impairs the above characteristics must be taken into account. Obesity certainly exerts an influence on the ventilatory response, preventing an adequate oxygenation. The main physiopathological mechanisms involved in 
the impairment of the uptake and management of $\mathrm{O}_{2}$ in obese individuals include a heightened demand for ventilation, increased work related to breathing, respiratory muscle inefficiency, and diminished respiratory compliance $[41,42]$.

Whether obesity is also a high-risk factor for developing HAPE still lacks sufficient evidence [5]. However, the two major theories for the cause of HAPE, exacerbated pulmonary hypertension and/or capillary alterations due to inflammatory mediators [43, 44], are in line with some pathophysiological effects seen in obese patients regardless of whether or not they are at high altitude. In fact, it has been observed that obese individuals present an obesityhypoventilation syndrome (OHS) accompanied by sleep disturbances, resulting in deep nocturnal oxygen desaturation and periodic apneic breathing [41, 45] even at moderate elevations. This syndrome elicits a severe hypoxemia and severe pulmonary hypertension [46]. A greater degree of alveolar hypoxia at altitude, which is aggravated by obesity, causes a further rise in PAP [47]. In addition, obese patients experience an increased inflammatory state, with the presence of inflammation mediators where increased levels of interleukin 6 have been described, along with other cytokines [48]. The above conditions are at the core of the current understanding of HAPE pathophysiology [44]. Therefore, the above mentioned factors are highly suggestive of a link between not only obesity and AMS but also between obesity and the development of HAPE.

\section{Obesity and Chronic Intermittent Exposure to High-Altitude Hypoxia}

Despite the fact that some studies suggest that exposure to $\mathrm{CIH}$ at moderate altitudes might be considered as a mean to lose body mass and improve metabolic risk factors [48-50] or that it has other beneficial effects [51], this condition (long-term $\mathrm{CIH}$ at high altitude) is a rather novel biological situation, and, for this reason, it is not fully and comprehensively understood or studied. Additionally, it is currently thought that the CIH model shares both exposure conditions: subjects experience acute exposure during the first days at high altitude and chronic exposure for extended periods of time $[11,16]$.

Contrary to current knowledge and concepts about lower BMIs being more prevalent in those experiencing acute or chronic exposure, recent available studies describe higher BMI values being prevalent in working populations exposed to $\mathrm{CIH}$. A recent study examining shifts over 15 days from the Kyrgyz at altitudes of 3,800-4,500 m demonstrated that obesity and overweight are common in workers in the high-altitude mining industry exposed to $\mathrm{CIH}$ [52]. Similarly, a high prevalence of increased BMIs was described in a previous study of soldiers working at 3,550 $\mathrm{m}$ (shifts, $5 \times 2$ days) [11] and in 76 young recruits during a followup at the same altitude [53]. These findings support the idea that this condition is fairly different than other types of CIH exposure, as mentioned above, at least in regard to its metabolic features.

Likewise, in lowlanders who migrated to an altitude of 3,500 m, those subjects with a higher BMI were more prone to have bad responses to hypoxia, highlighting that a higher BMI might be a risk factor for poor high-altitude acclimatization [54]. Additionally, during longer CIH shifts (months) at altitudes between 4,630 and 4,905 m, subjects with a BMI $>28 \mathrm{~kg} / \mathrm{m}^{2}$ had a higher PAP $(\sim 31 \mathrm{~mm} \mathrm{Hg})$ than those with a BMI of $22-24 \mathrm{~kg} / \mathrm{m}^{2}(\sim 22 \mathrm{~mm} \mathrm{Hg})$. Moreover, obese subjects were three times more susceptible to AMS than those with a normal BMI ( $97 \%$ vs. 37\%) [55]. Further support comes from Yang et al. [35], who demonstrated a positive correlation of a high BMI with the incidence of AMS at 3,658 m.

It is controversial whether other metabolic alterations associated with obesity, such as insulin resistance and type 2 diabetes mellitus, are affected by hypoxia. It has been noted that in subjects permanently residing at a high altitude, there is a decrease in obesity and a better 
regulation of glycemia [56]. However, there is recent evidence that under this condition, obese individuals maintain their sea-level insulin resistance and that it could even increase [53], a phenomenon also described for obstructive sleep apnea in humans and experimental animal models $[57,58]$. Most likely, this would affect only a certain group of individuals who would attain a susceptible metabolic disorder status, including obesity or overweight, but further studies are needed to confirm this hypothesis.

\section{Obesity and Chronic Exposure to High Altitude}

Despite the fact that initial epidemiological studies in residents of the Peruvian Andes reported obesity or metabolic syndrome as being rare at high altitude [59], recent evidence shows a sort of 'transitional pattern' [60] and links BMI to altitude-related illness. The most recent reports on long-term high-altitude residents have shown increases in cardiometabolic risks (metabolic syndrome), where a higher BMI is associated with lower oxygen saturation [61]. In concordance with this, it has also been demonstrated that a strong association exists between being overweight or having metabolic syndrome and excessive erythrocytosis (CMS) [62]. They have also found a larger prevalence of obesity and metabolic syndrome than previously reported.

To reconcile these contradictory findings, it must be remembered that the first reports considered a population with a different social and economic status that was from an agricultural society, whereas currently this society has suffered a 'westernization process' in order to catch up with the country's modernization and economic development. This has resulted in a remarkable change in lifestyles.

Interestingly, BMI, waist circumference, and waist-to-height ratio decrease with increasing altitude in Himalayan Tibetans, likely due to environmental conditions such as low temperatures and low oxygen levels, which could have a direct catabolic effect. Nevertheless, this finding is highly suggestive of genetic adaptations [63], as has been demonstrated for $\mathrm{Hb}$ genes [64].

Regarding HAPH, it has been reported that native subjects at altitudes between 4,630 and 4,905 $\mathrm{m}$ with a high BMI have a higher PAP ( $31 \mathrm{~mm} \mathrm{Hg})$ than those with a normal BMI [55].

\section{Obesity and Respiratory Impairment}

An important respiratory abnormality in obesity is a decrease in total respiratory system compliance. The resulting decrease in chest wall compliance is associated with the obese individual's accumulation of fat in and around the ribs, the diaphragm, and the abdomen [65]. As BMI increases (particularly in morbidly obese individuals), there is evidence of a reduction in expiratory flow and a decrease in forced expiratory volume in $1 \mathrm{~s}\left(\mathrm{FEV}_{1}\right)$ and forced vital capacity (FVC) [66]. The pattern of body fat distribution may also exert an influence on lung function [67]. Another study showed that a higher ratio of the abdominal circumference to hip circumference and higher subscapular skinfold thickness were negatively associated with $\mathrm{FEV}_{1}$ and FVC [68]. This latter finding suggests that central abdominal obesity has a greater impact on spirometric measures than back or lower body obesity.

In obese subjects, the sensation of dyspnea might come from an increase in the work required to breath to overcome the decrease in pulmonary compliance and the increase in resistance. Airway obstruction at low lung volumes may also stimulate flow receptors to increase the sensation of breathlessness $[69,70]$. 
Patients with obesity commonly develop OHS accompanied by sleep disturbances, resulting in deep nocturnal oxygen desaturation and periodic apneic breathing. The final result is increased hypoxemia, pulmonary hypertension, and a progressively worsening disability [41]. The same phenomena have been reported for overweight subjects [6, 70]. Interestingly, moderately obese subjects have a rather increased chemosensitivity to hypoxia and hypercapnia when compared with normal-weight subjects, but they are not able to increase their alveolar $\mathrm{pO}_{2}$ [45].

\section{Hypoxia and Adipose Tissue}

Perhaps, one of the most challenging issues in obesity is the role of adipose tissue as an 'organ' when its function is impaired by reduced blood supply, either internally or due to an external cause (hypoxic or hypobaric hypoxia), which has prompted an interesting and promising debate. Adipose tissue dysfunction is accompanied by insulin resistance, impaired adipose tissue capillarization, and higher adipose tissue gene expression of inflammatory cell markers, although relative hyperoxia does not modify these effects [71]. However, the same authors have demonstrated that exposing rats to mild hypoxic conditions ameliorates and even improves these alterations, concluding that metabolic responses to hypoxia are tightly linked to the severity, pattern, and duration of hypoxia exposure [72].

Although it seems clear that obesity and overweight, according to current knowledge, exert their most deleterious effects by aggravating hypoxemia at high altitude, thereby triggering the development of high altitude illnesses [5, 61], it is thus far not known how adipose tissue function and severe high-altitude hypoxemia interact. Further studies are required to further investigate this interaction.

\section{Conclusion}

Obesity and overweight pose big challenges for people going to moderate or high altitude, independent of the kind of exposure. Their functional and metabolic effects compromise proper acclimatization and contribute to the development of altitude-induced diseases, such as AMS and its more severe forms HAPH and CMS. Therefore, both overweight and obesity should be considered as conditioning factors, which in turn are modifiable.

\section{Funding}

This work was supported by GORE-Tarapaca BIP 30434827-0 grant

\section{Disclosure Statement}

The authors declared no conflicts of interest. 


\section{References}

1 Huicho L, Trelles M, Gonzales F, Mendoza W, Miranda J: Mortality profiles in a country facing epidemiological transition: an analysis of registered data. BMC Public Health 2009;9:47.

2 Lopez-Jaramillo P, Silva SY, Rodriguez-Salamanca N, Duran A, Mosquera W, Castillo V: Are nutrition-induced epigenetic changes the link between socioeconomic pathology and cardiovascular diseases? Am J Ther 2008; 15:362-372.

3 Leon-Velarde F, Maggiorini M, Reeves JT, Aldashev A, Asmus I, Bernardi L, Ge RL, Hackett P, Kobayashi T, Moore LG, Penaloza D, Richalet JP, Roach R, Wu T, Vargas E, Zubieta-Castillo G, Zubieta-Calleja G: Consensus statement on chronic and subacute high altitude diseases. High Alt Med Biol 2005;6:147-157.

4 Niermeyer S, Zamudio S, Moore IG: The people; in Hornbein T, Schoene R (eds): High Altitude: An Exploration of Human Adaptation. New York, Marcel Dekker, 2001, pp 43-100.

5 West JB, Schoene RB, Luks AM, Milledge JS: High Altitude Medicine and Physiology 5E. Boca Raton, CRC Press, Taylor and Francis Group, 2013, pp 544.

6 Hackett PH, Roach RC: High-altitude illness. N Engl J Med 2001;345:107-114.

7 Bartsch P, Swenson ER: Clinical practice: acute high-altitude illnesses. N Engl J Med 2013;368:2294-2302.

8 Maggiorini M, Buhler B, Walter M, Oelz O: Prevalence of acute mountain sickness in the Swiss Alps. BMJ 1990; 301:853-855.

9 Gaillard S, Dellasanta P, Loutan L, Kayser B: Awareness, prevalence, medication use, and risk factors of acute mountain sickness in tourists trekking around the Annapurnas in Nepal: a 12-year follow-up. High Alt Med Biol 2004;5:410-419.

10 Waeber B, Kayser B, Dumont L, Lysakowski C, Tramer MR, Elia N: Impact of study design on reported incidences of acute mountain sickness: a systematic review. High Alt Med Biol 2015;16:204-215.

11 Brito J, Siques P, Leon-Velarde F, de la Cruz JJ, Lopez V, Herruzo R: Chronic intermittent hypoxia at high altitude exposure for over 12 years: assessment of hematological, cardiovascular, and renal effects. High Alt Med Biol 2007;8:236-244.

12 Guijarro Morales A, Gil Extremera B, Maldonado Martin A: Acute mountain sickness. An Med Intern 1990;7: 375-378.

13 Richalet JP, Larmignat P, Poitrine E, Letournel M, Canoui-Poitrine F: Physiological risk factors for severe highaltitude illness: a prospective cohort study. Am J Respir Crit Care Med 2012;185:192-198.

14 Roach RC, Maes D, Sandoval D, Robergs RA, Icenogle M, Hinghofer-Szalkay H, Lium D, Loeppky JA: Exercise exacerbates acute mountain sickness at simulated high altitude. J Appl Physiol 2000;88:581-585.

15 Wu TY, Ding SQ, Zhang SL, Duan JQ, Li BY, Zhan ZY, Wu QL, Baomu S, Liang BZ, Han SR, Jie YL, Li G, Sun L, Kayser B: Altitude illness in Qinghai-Tibet railroad passengers. High Alt Med Biol 2010;11:189-198.

16 Richalet JP, Donoso MV, Jimenez D, Antezana AM, Hudson C, Cortes G, Osorio J, Leon A: Chilean miners commuting from sea level to $4500 \mathrm{~m}$ : a prospective study. High Alt Med Biol 2002;3:159-166.

17 Siques P, Brito J, Banegas JR, Leon-Velarde F, de la Cruz-Troca JJ, Lopez V, Naveas N, Herruzo R: Blood pressure responses in young adults first exposed to high altitude for 12 months at 3550 m. High Alt Med Biol 2009;10: 329-335.

18 Monge CC, Arregui A, Leon-Velarde F: Pathophysiology and epidemiology of chronic mountain sickness. Int J Sports Med 1992;13:S79-S81.

19 Penaloza D, Arias-Stella J: The heart and pulmonary circulation at high altitudes: healthy highlanders and chronic mountain sickness. Circulation 2007;115:1132-1146.

20 World Health Organization: Obesity: preventing and managing the global epidemic. Report of a WHO consultation. WHO Technical Report Series 2000;894:i-xii, 1-253. www.who.int/nutrition/publications/obesity/ WHO_TRS_894/en/ (last accessed August 2, 2017).

21 National Institutes of Health: Clinical guidelines on the identification, evaluation, and treatment of overweight and obesity in adults - the evidence report. Obes Res 1998;6(suppl 2):51S-209S.

22 Lawlor DA, Benfield L, Logue J, Tilling K, Howe LD, Fraser A, Cherry L, Watt P, Ness AR, Davey Smith G, Sattar $\mathrm{N}$ : Association between general and central adiposity in childhood, and change in these, with cardiovascular risk factors in adolescence: prospective cohort study. BMJ 2010;341:6224-6235.

23 Blundell JE, Dulloo AG, Salvador J, Fruhbeck G, EASO SAB Working Group on BMI: Beyond BMI - phenotyping the obesities. Obes Facts 2014;7:322-328.

24 Chan RS, Woo J: Prevention of overweight and obesity: how effective is the current public health approach. Int J Environ Res Public Health 2010;7:765-783.

25 Albala C, Vio F, Kain J, Uauy R: Nutrition transition in Chile: determinants and consequences. Public Health Nutr 2002;5:123-128.

26 Vio F, Albala C, Kain J: Nutrition transition in Chile revisited: mid-term evaluation of obesity goals for the period 2000-2010. Public Health Nutr 2008;11:405-412.

27 Finer N: Medical consequences of obesity. Medicine 2015;43:88-93.

28 Zarate A, Crestto M, Maiz A, Ravest G, Pino M, Valdivia G, Moreno M, Villarroel L: Influence of obesity on health care costs and absenteeism among employees of a mining company. Rev Méd Chile 2009;137:337-344.

29 Cawley J, Maclean JC: Unfit for service: the implications of rising obesity for US military recruitment. Health Econ 2012;21:1348-1366. 
Schneider M, Bernasch D, Weymann J, Holle R, Bartsch P: Acute mountain sickness: influence of susceptibility, preexposure, and ascent rate. Med Sci Sports Exerc 2002;34:1886-1891.

31 Vearrier D, Greenberg MI: Occupational health of miners at altitude: adverse health effects, toxic exposures, pre-placement screening, acclimatization, and worker surveillance. Clin Toxicol 2011;49:629-640.

32 Lopez JI, Holdridge A, Mendizabal JE: Altitude headache. Curr Pain Headache Rep 2013;17:383.

33 Ri-Li G, Chase PJ, Witkowski S, Wyrick BL, Stone JA, Levine BD, Babb TG: Obesity: associations with acute mountain sickness. Ann Intern Med 2003;139:253-257.

34 Hirata K, Masuyama S, Saito A: Obesity as risk factor for acute mountain sickness. Lancet 1989;2:1040-1041.

35 Yang B, Sun ZJ, Cao F, Zhao H, Li CW, Zhang J: Obesity is a risk factor for acute mountain sickness: a prospective study in Tibet railway construction workers on Tibetan plateau. Eur Rev Med Pharmacol Sci 2015;19:119122.

36 Honigman B, Theis MK, Koziol-McLain J, Roach R, Yip R, Houston C, Moore LG, Pearce P: Acute mountain sickness in a general tourist population at moderate altitudes. Ann Intern Med 1993;118:587-592.

37 Kayser B: Acute mountain sickness in western tourists around the Thorong pass (5400 m) in Nepal. J Wilderness Med 1991:2:110-117.

38 Ziaee V, Yunesian M, Ahmadinejad Z, Halabchi F, Kordi R, Alizadeh R, Afsharjoo HR: Acute mountain sickness in Iranian trekkers around Mount Damavand (5671 m) in Iran. Wilderness Environ Med 2003;14:214-219.

39 Gallagher SA, Hackett PH: High-altitude illness. Emerg Med Clin North Am 2004;22:329-355.

40 You H, Li X, Pei T, Huang Q, Liu F, Gao Y: Predictive value of basal exhaled nitric oxide and carbon monoxide for acute mountain sickness. Wilderness Environ Med 2012;23:316-324.

41 Parameswaran K, Todd DC, Soth M: Altered respiratory physiology in obesity. Can Respir J 2006;13:203-210.

42 Sood A: Does obesity weigh heavily on the health of the human airway? J Allergy Clin Immunol 2005;115: 921-924.

43 Luks AM, McIntosh SE, Grissom CK, Auerbach PS, Rodway GW, Schoene RB, Zafren K, Hackett PH: Wilderness medical society consensus guidelines for the prevention and treatment of acute altitude illness. Wilderness Environ Med 2010;21:146-155.

44 Swenson ER, Bartsch P: High-altitude pulmonary edema. Compr Physiol 2012;2:2753-2773.

45 Ge RL, Stone JA, Levine BD, Babb TG: Exaggerated respiratory chemosensitivity and association with $\mathrm{SaO}_{2}$ level at $3568 \mathrm{~m}$ in obesity. Respir Physiol Neurobiol 2005;146:47-54.

46 Valencia-Flores M, Rebollar V, Santiago V, Orea A, Rodriguez C, Resendiz M, Castano A, Roblero J, Campos RM, Oseguera J, Garcia-Ramos G, Bliwise DL: Prevalence of pulmonary hypertension and its association with respiratory disturbances in obese patients living at moderately high altitude. Int J Obes Relat Metab Disord 2004; $28: 1174-1180$

47 Toff NJ: Hazards of air travel for the obese: Miss Pickwick and the Boeing 747. J R Coll Physicians Lond 1993; 27:375-376.

48 Kayser B, Verges S: Hypoxia, energy balance and obesity: from pathophysiological mechanisms to new treatment strategies. Obes Rev 2013;14:579-592.

49 Westerterp KR, Kayser B, Wouters L, Le Trong JL, Richalet JP: Energy balance at high altitude of 6,542 m. J Appl Physiol 1994;77:862-866.

50 Lippl FJ, Neubauer S, Schipfer S, Lichter N, Tufman A, Otto B, Fischer R: Hypobaric hypoxia causes body weight reduction in obese subjects. Obesity (Silver Spring) 2010;18:675-681.

51 Serebrovskaya TV: Intermittent hypoxia research in the former Soviet Union and the Commonwealth of Independent States: history and review of the concept and selected applications. High Alt Med Biol 2002;3:205221.

52 Esenamanova MK, Kochkorova FA, Tsivinskaya TA, Vinnikov D, Aikimbaev K: Chronic intermittent high altitude exposure, occupation, and body mass index in workers of mining industry. High Alt Med Biol 2014; 15:412-417.

53 Siques P: Metabolic determinants and aclimatization in cronic intermittent exposure to high altitude (in Spanish); in Osorio J, Siques P, Brito J (eds): Vivir y trabajar en altura. Iquique, Osar, 2014, pp 43-54.

54 Peng QQ, Basang Z, Cui CY, Li L, Qian J, Gesang Q, Yang L, La Z, De Y, Dawa P, Qu N, Suo Q, Dan Z, Xiao D, Wang XF, Jin L: Physiological responses and evaluation of effects of BMI, smoking and drinking in high altitude acclimatization: a cohort study in Chinese Han young males. PLoS One 2013;8:e79346.

55 Wu TY, Ding SQ, Liu JL, Yu MT, Jia JH, Chai ZC, Dai RC, Zhang SL, Li BY, Pan L, Liang BZ, Zhao JZ, Qi T, Sun YF, Kayser B: Who should not go high: chronic disease and work at altitude during construction of the QinghaiTibet railroad. High Alt Med Biol 2007;8:88-107.

56 Quintero P, Milagro FI, Campion J, Martinez JA: Impact of oxygen availability on body weight management. Med Hypotheses 2010;74:901-907.

57 Turgut Celen Y, Peker Y: Cardiovascular consequences of sleep apnea: II-Cardiovascular mechanisms. Anadolu Kardiyol Derg 2010;10:168-175.

58 Drager LF, Lopes HF, Maki-Nunes C, Trombetta IC, Toschi-Dias E, Alves MJ, Fraga RF, Jun JC, Negrao CE, Krieger EM, Polotsky VY, Lorenzi-Filho G: The impact of obstructive sleep apnea on metabolic and inflammatory markers in consecutive patients with metabolic syndrome. PLoS One 2010;5:e12065.

59 Rotta A, Morales SG, Battilana G: Valores de colesterol sanguíneo y de presión arterial en sujetos sanos, de nivel del mar y de la altura. Reporte preliminar. Rev Peru Cardiol 1965;12:9-15. 
San Martin et al.: Obesity as a Conditioning Factor for High-Altitude Diseases

60 Mohanna S, Baracco R, Seclen S: Lipid profile, waist circumference, and body mass index in a high altitude population. High Alt Med Biol 2006; 7:245-255.

61 Miele CH, Schwartz AR, Gilman RH, Pham L, Wise RA, Davila-Roman VG, Jun JC, Polotsky VY, Miranda JJ, LeonVelarde F, Checkley W: Increased cardiometabolic risk and worsening hypoxemia at high altitude. High Alt Med Biol 2016;17:93-100.

62 De Ferrari A, Miranda JJ, Gilman RH, Davila-Roman VG, Leon-Velarde F, Rivera-Ch M, Huicho L, Bernabe-Ortiz A, Wise RA, Checkley W; CRONICAS Cohort Study Group: Prevalence, clinical profile, iron status, and subjectspecific traits for excessive erythrocytosis in Andean adults living permanently at 3,825 meters above sea level. Chest 2014;146:1327-1336.

63 Sherpa LY, Deji, Stigum H, Chongsuvivatwong V, Thelle DS, Bjertness E: Obesity in Tibetans aged 30-70 living at different altitudes under the north and south faces of Mt. Everest. Int J Environ Res Public Health 2010; 7: $1670-1680$.

64 Beall CM: Detecting natural selection in high-altitude human populations. Respir Physiol Neurobiol 2007;158: 161-171.

65 Naimark A, Cherniack RM: Compliance of the respiratory system and its components in health and obesity. J Appl Physiol 1960;15:377-382.

66 Ray CS, Sue DY, Bray G, Hansen JE, Wasserman K: Effects of obesity on respiratory function. Am Rev Respir Dis 1983;128:501-506.

67 Collins LC, Hoberty PD, Walker JF, Fletcher EC, Peiris AN: The effect of body fat distribution on pulmonary function tests. Chest 1995;107:1298-1302.

68 Lazarus R, Sparrow D, Weiss ST: Effects of obesity and fat distribution on ventilatory function: the normative aging study. Chest 1997;111:891-898.

69 Pankow W, Podszus T, Gutheil T, Penzel T, Peter J, Von Wichert P: Expiratory flow limitation and intrinsic positive end-expiratory pressure in obesity. J Appl Physiol 1998;85:1236-1243.

70 Sahebjami H: Dyspnea in obese healthy men. Chest 1998;114:1373-1377.

71 Goossens GH, Bizzarri A, Venteclef N, Essers Y, Cleutjens JP, Konings E, Jocken JW, Cajlakovic M, Ribitsch V, Clement $\mathrm{K}$, Blaak EE: Increased adipose tissue oxygen tension in obese compared with lean men is accompanied by insulin resistance, impaired adipose tissue capillarization, and inflammation. Circulation 2011;124: 67-76.

72 Goossens GH, Blaak EE: Adipose tissue dysfunction and impaired metabolic health in human obesity: a matter of oxygen? Front Endocrinol 2015;6:55. 